\title{
Correction to: Impact of systematic screening for AmpC-hyperproducing Enterobacterales intestinal carriage in intensive care unit patients
}

\author{
Elsa Manquat ${ }^{*}$ (D) Matthieu Le Dorze ${ }^{1,5}$, Gauthier Pean De Ponfly ${ }^{2}$, Hanaa Benmansour ${ }^{2}$, Rishma Amarsy ${ }^{3}$, \\ Emmanuelle Cambau ${ }^{2,4}$, Benjamin Soyer ${ }^{1}$, Benjamin Glenn Chousterman ${ }^{1,5}$ and Hervé Jacquier ${ }^{2,4}$
}

Correction to: Ann Intensive Care (2020) 10:149.

https://doi.org/10.1186/s13613-020-00754-9

After publication of the original article [1], an error was identified in the authors' names. The given names and family names were all erroneously transposed.

The correct authors' names are:

Elsa: given name

Manquat: family name

Matthieu: given name

Le Dorze: family name

Gauthier: given name

Pean De Ponflly: family name

Hanaa: given name

Benmansour: family name

Rishma: given name

Amarsy: family name

Emmanuelle: given name

Cambau: family name

Benjamin: given name

Soyer: family name

The original article can be found online at https://doi.org/10.1186/s13613 020-00754-9.
Benjamin Glenn: given name Chousterman: family name

Hervé: given name

Jacquier: family name

The original article has been corrected.

\begin{abstract}
Author details
${ }^{1}$ Service de Réanimation Chirurgicale Polyvalente, Département d'Anesthésie Réanimation, Hôpital Lariboisière, AP-HP, 2 Rue Ambroise Paré, 75475 Paris Cedex 10, France. ${ }^{2}$ Laboratoire de Bactériologie-Virologie, Hôpital Lariboisière, AP-HP, 2 Rue Ambroise Paré, 75475 Paris Cedex 10, France. ${ }^{3}$ Equipe Opérationnelle d'Hygiène, Hôpital Lariboisière, AP-HP, 2 Rue Ambroise Paré, 75475 Paris Cedex 10, France. ${ }^{4}$ UMR1137, IAME, University of Paris, Paris, France. ${ }^{5}$ UMRS942, Mascot, University of Paris, Paris, France.
\end{abstract}

Published online: 26 May 2021

\section{Reference}

1. Elsa, et al. Impact of systematic screening for AmpC-hyperproducing Enterobacterales intestinal carriage in intensive care unit patient. Ann Intensive Care. 2020;10:149. https://doi.org/10.1186/s13613-020-00754-9.

\section{Publisher's Note}

Springer Nature remains neutral with regard to jurisdictional claims in published maps and institutional affiliations.

${ }^{*}$ Correspondence: elsa.manquat@gmail.com

${ }^{1}$ Service de Réanimation Chirurgicale Polyvalente, Département d'Anesthésie Réanimation, Hôpital Lariboisière, AP-HP, 2 Rue Ambroise Paré, 75475 Paris Cedex 10, France

Full list of author information is available at the end of the article adaptation, distribution and reproduction in any medium or format, as long as you give appropriate credit to the original author(s) and the source, provide a link to the Creative Commons licence, and indicate if changes were made. The images or other third party material in this article are included in the article's Creative Commons licence, unless indicated otherwise in a credit line to the material. If material is not included in the article's Creative Commons licence and your intended use is not permitted by statutory regulation or exceeds the permitted use, you will need to obtain permission directly from the copyright holder. To view a copy of this licence, visit http://creativecommons.org/licenses/by/4.0/. 